WE investigated whether Clostridium difficile toxin alters colonic tissue levels of vasoactive intestinal peptide (VIP) at the expense of changes in colonic motility in the isolated perfused rabbit left colon. Colonic inflammation was induced by the intracolonic administration of $10^{-8} M C$. diffi cile toxin. Strain gauge transducers were sewn onto the serosal surface of the colon to evaluate colonic motility. $C$. difficile administration produced histologic changes consistent with epithelial damage. This was associated with an increased production of prostaglandin $E_{2}$ and thromboxane $B_{2}$. Tissue levels of VIP but not substance $P$ were significantly reduced. This was associated with an increased number of contractions per minute and an average force of each colonic contraction. These results suggest that tissue levels of VIP are suppressed by $C$. difficile and may participate in colonic dysmotility during active inflammation.

Key words: Clostridium difficile, motility, prostanoids, vasoactive intestinal peptide

\section{Clostridium difficile suppresses colonic vasoactive intestinal peptide associated with altered motility}

\author{
A. Nassif, W. E. Longo, ${ }^{\text {CA }}$ R. Sexe, M. Stratton, \\ J. Standeven, A. M. Vernava and D. L. Kaminski
}

Department of Surgery, The Surgical Research Institute, St. Louis University School of Medicine, St. Louis, MO, USA

${ }^{\mathrm{CA}}$ Corresponding Author

\section{Introduction}

Clostridium difficile toxin is the causative agent of pseudomembranous colitis. This disease entity is associated with watery diarrhoea and altered motility, and is often effectively treated with enteral antibiotics. ${ }^{1}$ Colonic neuropeptides such as VIP and substance $\mathrm{P}$ are abundant in the gut and maintain various physiological functions, such as regulation of colonic motility. We have previously demonstrated that platelet-activating factor (PAF) increases colonic tissue levels of VIP and substance $\mathrm{P}$ which were inhibited by a specific PAF antagonist. ${ }^{2}$ In contrast, in further studies we found that trinitrobenzene (TNB) suppresses levels of these neuropeptides, which were ameliorated by neural blockade. ${ }^{3}$ The aim of the present study was to evaluate the possible role of endogenous VIP and substance P in the dysmotility changes of the left colon of the rabbit to Clostridium difficile toxin.

\section{Materials and Methods}

The experimental procedure for producing colonic inflammation by other agents known to induce colitis in the isolated rabbit colon has been reported previously. ${ }^{4}$ After isolating the colon, it was placed on a temperature controlled base, humidified whole organ perfusion apparatus ( $\mathrm{Mx}$ International, Aurora, $\mathrm{CO}$ ) and allowed to equilibrate with an intra-arterial Kreb's Ringers bicarbonate (KRB) infusion for the first $30 \mathrm{~min}$ period. This was followed by the intraluminal infusion of $10^{-8} \mathrm{M} C$. difficile toxin while continuing intra-arterial infusion of KRB for $30 \mathrm{~min}$. At the end of this period, C. difficile was discontinued and the colon was allowed to recover for $30 \mathrm{~min}$, infusing only KRB intra-arterially. In a separate set of experiments, KRB was infused intraluminally during the entire $90 \mathrm{~min}$ period. Strain gauge transducers were sewn onto the serosal surface of the colon to measure colonic motility. Motility was calculated as four indices: (1) contractions/min; (2) peak force per contraction measured in grams; (3) average force per contraction; and (4) the minute motility index (MMI) calculated as the sum of the contractions, weighed by the peak force, and expressed as a per minute average. At the end of the experiment, tissue samples of colon were taken and immersed in liquid nitrogen and then stored at $-70^{\circ} \mathrm{C}$. A second section of colon was taken and evaluated histologically to determine the extent of inflammation. Tissue levels of prostaglandin $\mathrm{E}_{2}$ $\left(\mathrm{PGE}_{2}\right)$, thromboxane $\mathrm{B}_{2}\left(\mathrm{TxB}_{2}\right)$, VIP and substance $\mathrm{P}$ were determined by well described radioimmunoassays. ${ }^{3,5}$

\section{Results}

No colitis was observed in KRB treated colons. C. difficile treated colons demonstrated evidence of inflammation that was confined to the mucosa 
Table 1. The effect of $C$. difficile on tissue $\mathrm{PGE}_{2}, \mathrm{TxB}_{2}, \mathrm{VIP}$, substance $P$ and colonic motility

\begin{tabular}{lcc}
\hline & $\begin{array}{c}\text { KRB } \\
(n=4)\end{array}$ & $\begin{array}{c}\text { C. difficile } \\
(n=4)\end{array}$ \\
\hline Tissue VIP levels $^{\mathrm{a}}$ & $221.2 \pm 31.6$ & $107.6 \pm 16.4^{*}$ \\
Tissue SP levels $^{\mathrm{a}}$ & $164.6 \pm 27.7$ & $179.1 \pm 13.5$ \\
Tissue PGE $_{2}$ levels & $25.2 \pm 6.4$ & $174.8 \pm 31.9^{*}$ \\
Tissue TxB levels $_{\text {Contractions/min }}$ & $18.7 \pm 5.4$ & $32.4 \pm 8.8^{*}$ \\
Peak force $^{\mathrm{b}}$ & $10.9 \pm 3.5$ & $14.7 \pm 3.3^{*}$ \\
Average force $^{\mathrm{c}}$ & $2.5 \pm 0.11$ & $1.9 \pm 0.09$ \\
MMI $^{\mathrm{d}}$ & $0.44 \pm 0.3$ & $0.72 \pm 0.08^{*}$ \\
\hline
\end{tabular}

" $p<0.05, C$. difficile and KRB.

${ }^{\mathrm{a}} \mathrm{pg} / \mathrm{mg}$ wet tissue.

${ }^{b}$ Peak force per contraction.

${ }^{\mathrm{C}}$ Average force per contraction.

${ }^{\mathrm{d}}$ Minute Motility Index.

and submucosa and did not involve the muscularis propria. Tissue concentrations of $\mathrm{PGE}_{2}$ and $\mathrm{TxB}_{2}$ in $C$. difficile treated colons were significantly increased compared to KRB treated colons. Tissue levels of VIP were significantly suppressed while levels of substance $P$ remained unchanged in $C$. difficile treated colons. Motility results demonstrated that $C$. difficile increased both the number of contractions per min and the average force per contraction (Table 1).

\section{Discussion}

Our results demonstrate that $C$. difficile toxin produces a significant inflammatory response and altered colonic motility that correlates with alterations in tissue levels of VIP. A recent study ${ }^{6}$ utilizing $C$. difficile toxin A on rabbit distal colonic loops demonstrated an increased number of spike bursts without altering slow-wave frequency that was associated with increased production of prostanoids and leukotrienes. The authors concluded that this result may be indirect resulting from the production of motility altering arachidonic acid metabolites. The results were similar to that seen by Gilbert $^{7}$ who demonstrated that similar alterations in ileal circular smooth muscle myoelectric and contractile activity were seen with toxin A.

Other investigators, as well as our own, have demonstrated that disturbances in colonic motility may be related to fluctuating levels of IL-1,
PAF and eicosanoids in both TNB and PAF models of colonic inflammation. ${ }^{3,8-10}$ We speculate from our previous studies involving altera. tions in colonic neuropeptides that disturbance in colonic motility may be related to a mechanism involving arachidonic acid metabolites released during inflammation and neuropeptide fluctuations. Presently, our data suggest that VIP is suppressed by $C$. difficile and may participate in colonic dysmotility disturbances during inflammatory states of the left colon. Studies are in progress to determine whether neural blockade or pretreatment with synthetic VIP antagonists antagonize the changes in neuropeptide release, inflammation and motility changes seen by $C$. difficile.

\section{References}

1. Larson $\mathrm{AE}$, Price $\mathrm{AB}$. Pseudomembranous colitis: presence of Clostridial toxin. Lancet 1977; 2: 1312-1324.

2. Deshpande Y, Longo WE, Chandel B, et al. Effect of platelet-activating factor (PAF) and its antagonists on colonic dysmotility and tissue levels of colonic neuropeptides. Eur J Pharmacol 1994; 256: 121-123.

3. Sexe R, Stratton M, Nassif A, Kaminski DL, Longo WE. Lidocaine amelio rates trinitrobenzene sulfonic acid suppression of tissue levels of colonic neuropeptides. Surg Research Comm (in press).

4. Chandel B, Niehoff M, Deshpande Y, Standeven J, Vernava AM, Kaminski DL, Longo WE. The isolated perfused colon: a novel model to study colonic inflammation and motility. Surg Research Comm 1994; 16: 125129 .

5. Kaminski DL, Andrus CH, German D, Deshpande YG. The role of prostanoids in the production of acute acalculous cholecystitis by platelet activating factor (PAF). Ann Surg 1990; 212: 455-461.

6. Burakokk R, Zhao L, Celifarco AJ, Rose KL, Donovan V, Pothoulakis C Percy WH. Effects of purified Clostridium difficile toxin A on rabbit distal colon. Gastroenterology 1995; 109: 348-354.

7. Gilbert R, Triadafilopoulos G, Pothoulakis C, Giampaolo C, Lamont JT. Effect of purified $C$. difficile toxin on intestinal smooth muscle. Am J Physiol 1989; 256: G759-G766.

8. Pons L, Droy-Lefaix MT, Bveno L. Leukotriene D4 participates in colonic transit disturbances induced by intracolonic administration of trinitrobenzene sulfonic acid in rats. Gastroenterology 1992; 102: 149-156.

9. Morteav O, More J, Pons L, Lveno L. Platelet-activating factor and inter leukin- 1 are involved in colonic dysmotility in experimental colitis in rats. Gastroenterology 1993; 104: 47-56.

10. Longo WE, Standeven J, Chandel B, Deshpande Y, Vernava AM, Kaminski DL. Platelet-activating factor mediates trinitrobenzene induced dysmotility in the left colon. Mediators of Inflammation 1995; 4: 17-18.

ACKNOWLEDGEMENT. This study was supported by USPHS Grant DK 27695.

Received 22 August 1995; accepted 28 August 1995 


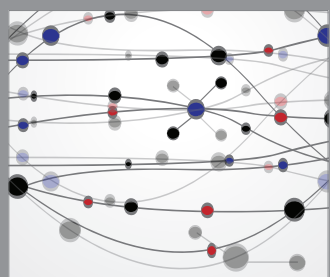

The Scientific World Journal
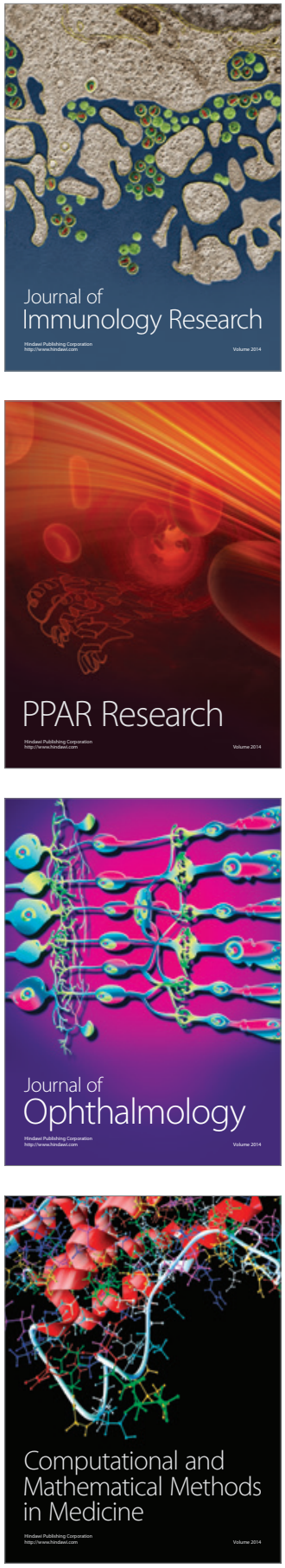

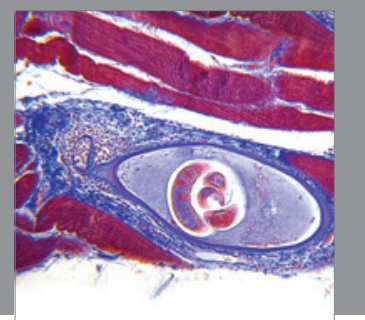

Gastroenterology

Research and Practice
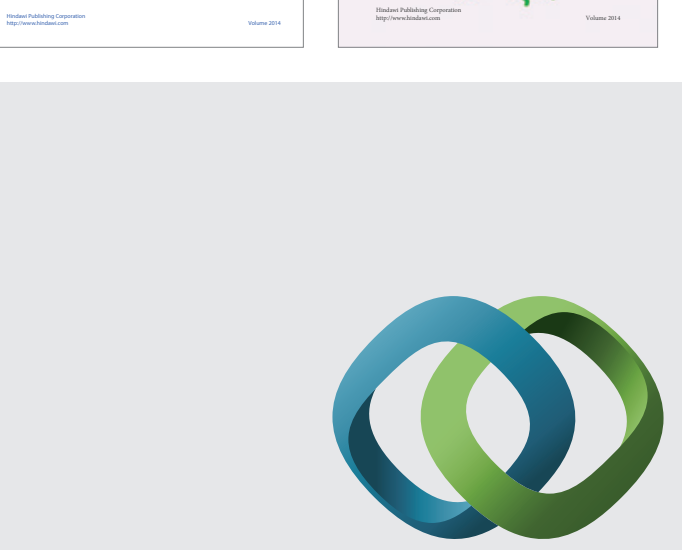

\section{Hindawi}

Submit your manuscripts at

http://www.hindawi.com
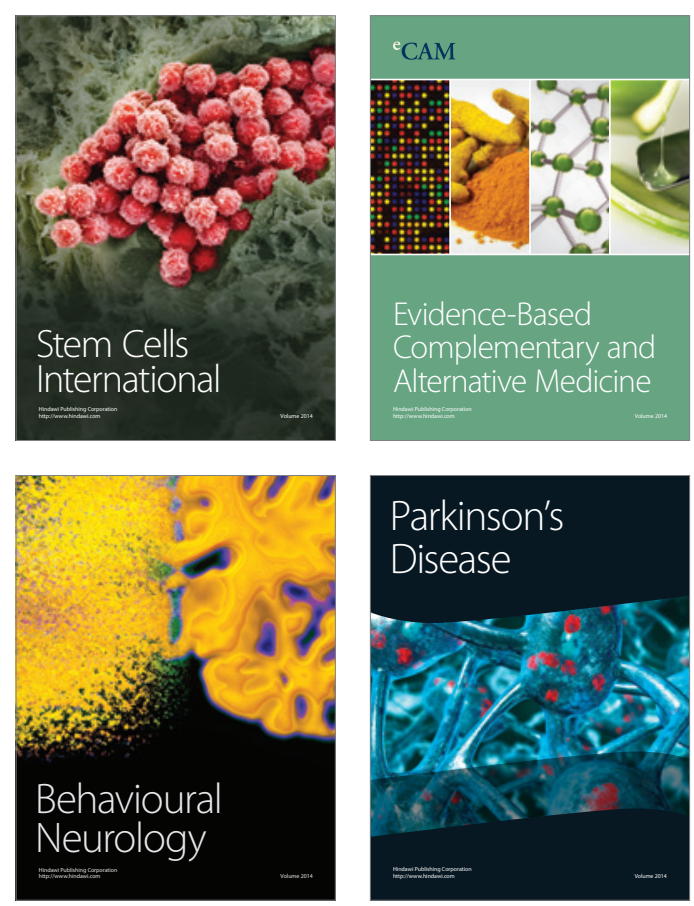

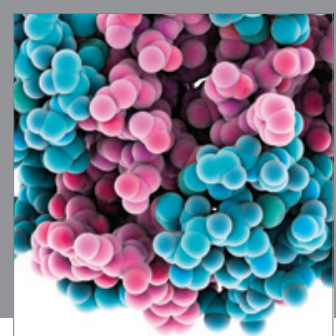

Journal of
Diabetes Research

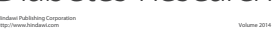

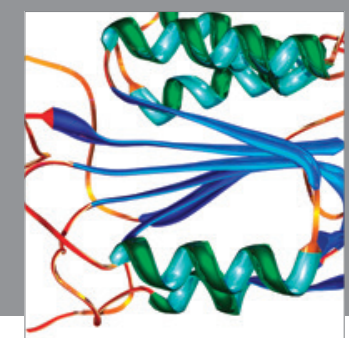

Disease Markers
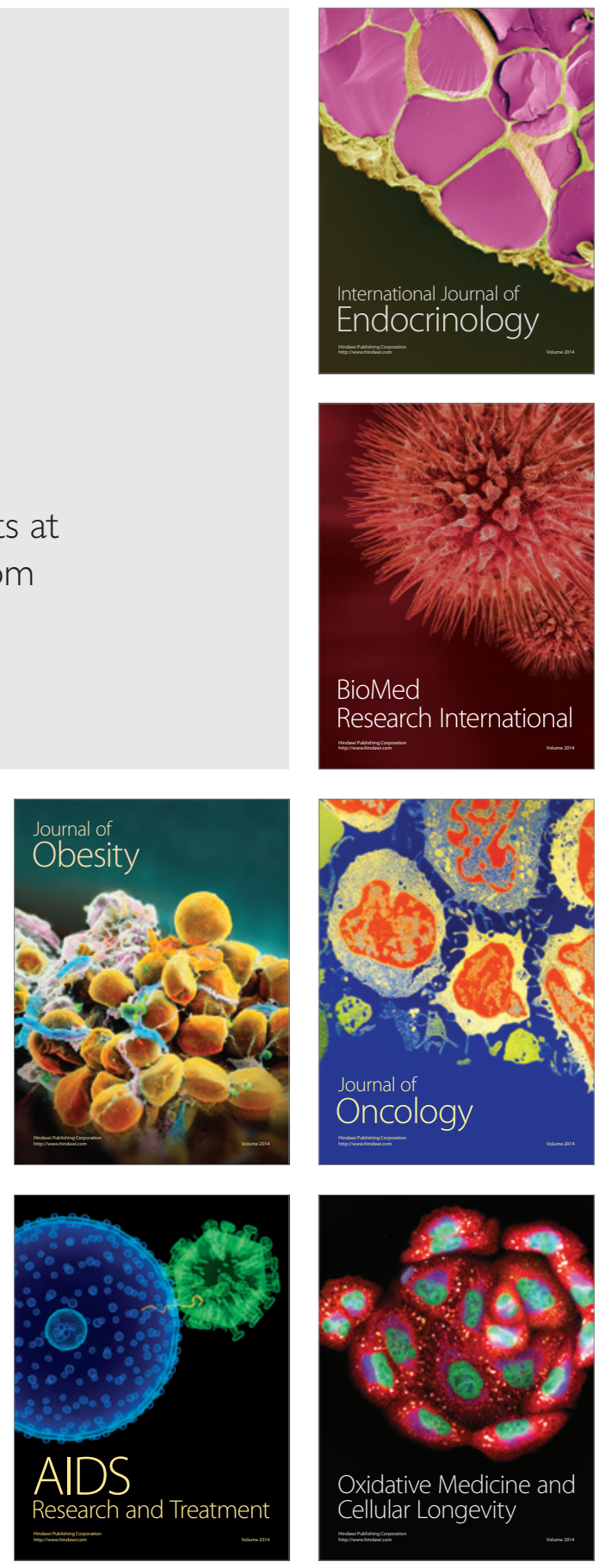